\title{
Gas Separation Membranes Prepared with Copolymers of Perfluoro(2-methylene-4,5-dimethyl-1,3-dioxlane) and Chlorotrifluoroethylene
}

Minfeng Fang a, Yoshiyuki Okamoto a, ${ }^{a}$, Yasuhiro Koike ${ }^{b}$, Zhenjie $\mathrm{He}^{c}$ and Timothy C. Merkel ${ }^{\mathrm{c}}$

a Department of Chemical and Biomolecular Engineering, Tandon School of Engineering, New York University, 6 MetroTech Center, Brooklyn, NY 11201, USA

b Faculty of Science and Technology, Keio University, Yokohama 223-8522, Japan

${ }^{c}$ Membrane Technology and Research, Inc., 39630 Eureka Drive, Newark, CA 94560, USA

* Corresponding author. Tel: +1 718260 3638, E-mail address: yo407@nyu.edu 


\section{GRAPHICAL ABSTRACT}

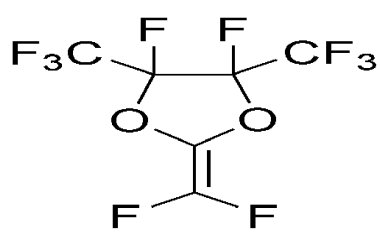

PFMDD<smiles>FC(F)C(F)Cl</smiles>

CTFE

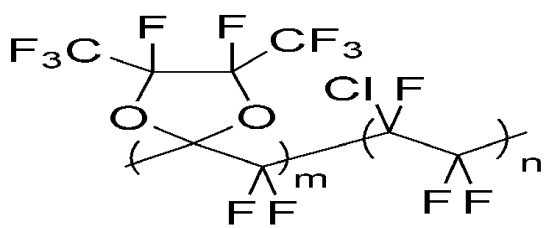

poly(PFMDD-co-CTFE)

A new fluoropolymer, the copolymer of perfluoro(2-methylene-4,5-dimethyl-1,3-

dioxolane) (PFMDD) and chlorotrifluoroethlyene (CTFE) has been prepared with different compositions. The composite membranes fabricated from the poly(PFMDD-co-CTFE) demonstrate far superior gas separation performance compared to the commercial perfluoropolymers for the separation of gas pairs of $\mathrm{H}_{2} / \mathrm{CH}_{4}, \mathrm{He} / \mathrm{CH}_{4}$, and $\mathrm{CO}_{2} / \mathrm{CH}_{4}$. 


\section{Abstract}

Several families of hydrocarbon polymers (polysulfones, polycarbonates, cellulose acetates, polyamides, and polyimides) have been established as common industrial gas separation membranes over the past three decades. Fluoropolymer membranes have found commercial use because of their unique gas separation properties in addition to their extraordinary chemical resistance and thermo-oxidative stability. To date, studies of gas transport in fluoropolymers have been limited largely to variants of the commercially available perfluoropolymers: Teflon ${ }^{\circledR} A F$, Cytop ${ }^{\mathrm{TM}}$, and Hyflon® AD. Here, we describe gas transport in composite membranes fabricated from copolymers of perfluoro(2-methylene-4,5-dimethyl-1,3-dioxolane) (PFMDD) and chlorotrifluoroethlyene (CTFE). This poly(PFMDD-co-CTFE)-based membranes have far superior gas separation performance compared to the commercial 
perfluoropolymers for a number of gas pairs, including $\mathrm{H}_{2} / \mathrm{CH}_{4}, \mathrm{He} / \mathrm{CH}_{4}$, and $\mathrm{CO}_{2} / \mathrm{CH}_{4}$. The gas separation performance of the membranes depends strongly on the copolymer composition. Increasing the amount of CTFE up to $30 \mathrm{~mol} \%$ in the copolymer increases the membrane selectivity and reduces permeance. The membranes based on 70 mol\% PFMDD-30 mol\% CTFE poly(PFMDD-co-CTFE) show $\mathrm{H}_{2} / \mathrm{CH}_{4}$ and $\mathrm{He} / \mathrm{CH}_{4}$ selectivities of 210 and 480 , respectively, values that far exceed those possible with the known commercial perfluoropolymers.

Keywords: gas separation membrane; perfluoropolymer; perfluoro dioxolane; chlorotrifluoroethylene; poly(PFMDD-co-CTFE) 


\section{Introduction}

Polymeric gas separation membranes have become widely used for a variety of industrial gas separations applications over the past three decades and several polymers have been established as common gas separation membranes, including polysulfones, polycarbonates, cellulose acetates, polyamides, and polyimides [1]. Fluoropolymers as a new class of membrane material have attracted increasing interest due to their unique properties including the extremely high chemical resistance and extraordinary thermo-oxidative stability, improved separation performance as well as plasticization resistance [1, 2]. The use of fluoropolymers for gas separations has drawn great attention ever since the development of commercial perfluoropolymers under trade names Teflon $\AA$ AF, Cytop ${ }^{\mathrm{TM}}$, and Hyflon® AD. These perfluoropolymers are amorphous and solvent-processable, resulting in relatively high gas permeability and the feasibility to process them by solution casting and coating methods used in the membrane industry [3]. The gas transport properties of these commercial perfluoropolymers have been studied extensively over the past 25 years [4-13]. The perfluoropolymers have unique gas separation properties and in some cases they exceed the selectivity-permeability upper bound relationship originally described by Robeson [14]. However, new amorphous and solvent-processable fluoropolymers with higher selectivity are still highly desirable.

In the search for new, improved perfluoropolymers for gas separation membranes, we have previously prepared copolymers of perfluoro(2-methlyene4,5-dimethyl-1,3-dioxolane) (PFMDD) and perfluoro(2-methylene-1,3-dioxolane) 
(PFMD) (I, Scheme 1) [3]. The homopolymer of PFMDD is amorphous, while the homopolymer of PFMD is crystalline and does not dissolve in organic solvents. When PFMDD and PFMD are copolymerized, the resulting poly(PFMDD-coPFMD) is amorphous when the content of PFMD is less than $70 \mathrm{~mol} \%$, and the amorphous poly(PFMDD-co-PFMD) exhibited superior gas separation performance for a number of important gas pairs [3]. We found that when the amount of the PFMD monomer in the copolymer is increased, the gas permeance shows a modest decline, but the size selectivity is dramatically increased. For example, the $\mathrm{H}_{2} / \mathrm{CH}_{4}$ selectivity of the membrane increases from 50 to 130 as the PFMD monomer content is increased from 26 to 57 wt\%. This effect is rationalized by the fact that the absence of substituents on its 4 and 5 positions allows the PFMD monomer to pack more efficiently than PFMDD, giving a more ordered and tighter chain structure that is better for sieving gas molecules. The combination of PFMDD and PFMD in varied amounts allows the gas permeation properties of the resulting copolymer to be tuned very effectively.

In a continuing effort to identify highly selective fluoropolymers for gas separations, we aimed to prepare new fluoropolymers derived from copolymerization of the bulky PFMDD monomer and a small fluorinated monomer that might exhibit tight chain packing. Chlorotrifluoroethylene (CTFE) is the most widely used fluoroalkene after tertrafluoroethylene (TFE) [15-17]. CTFE is a smaller molecule than PFMD and is known to pack efficiently as a polymer. In fact, polychlorotrifluoroethylene (PCTFE) is highly crystalline and does not dissolve in most organic solvents including fluorinated solvents, and it is known 
as one of the best gas barrier materials [18]. CTFE is readily copolymerized with various vinyl monomers to yield novel copolymers $[19,20]$. We have previously prepared copolymers of a perfluoro dioxolane monomer with CTFE using a free radical initiator in bulk or in solution [21]. The polymers obtained are soluble in fluorinated solvents such as hexafluorobenzene and perfluoro-2butyltetrahydrofuran (Fluorinert® FC-75). The films of the copolymers are flexible, chemically and thermally stable, and highly transparent.

Thus herein we describe a new fluoropolymer, the copolymer of PFMDD and CTFE (II, Scheme 1) for gas separation. The physical properties as well as the gas separation performance of the copolymers were investigated.

\section{Results and Discussion}

The poly(PFMDD-Co-CTFE) copolymers appear as white powder and the yield was about $80-90 \%$ based on the amount of PFMDD monomer in feed. The compositions of the copolymers can be estimated from ${ }^{19} \mathrm{~F}$ NMR spectra, as shown in Figure 1. The peak at ca. -80 ppm is assigned to the two $-\mathrm{CF}_{3}$ groups located on the 4 and 5 position of the dioxolane ring of PFMDD unit; a group of broad and overlapped peaks from -100 to -130 ppm are attributed to the $-\mathrm{CF}_{2}-$ and-CCIF- units [22-24] on the polymer backbone as well as the two -CFgroups of the dioxolane ring. By using the integrals of the $-\mathrm{CF}_{3}$ peak and the region of -100 to $-130 \mathrm{ppm}$ from both the spectra of poly(PFMDD-co-CTFE) copolymer and the PFMDD homopolymer, the fraction of CTFE in the copolymers can be estimated. 
The difference of peak integrals in the -100 to $-130 \mathrm{ppm}$ range is attributed to the presence of CTFE units in the polymer backbone.

Table 1 summarizes the compositions as well as other physical properties of four poly(PFMDD-co-CTFE) samples. The estimated CTFE content in the copolymers using the NMR data is $12 \mathrm{~mol} \%, 17 \mathrm{~mol} \%, 30 \mathrm{~mol} \%$, and $52 \mathrm{~mol} \%$ for sample B1, B2, B3, and B4, respectively. The exact compositions of the corresponding samples were also determined by elemental analysis data. Using the $\mathrm{Cl}$ data, the CTFE content in the copolymers is calculated to be $10 \mathrm{~mol} \%, 11 \mathrm{~mol} \%, 28 \mathrm{~mol} \%$, and 50 mol\% for sample B1, B2, B3, and B4, respectively. This indicates sample B1 and B2 are almost identical in composition, as verified by the same $T_{g}$ value $\left(152^{\circ} \mathrm{C}\right)$. Since PCTFE has a lower $T_{g}\left(75^{\circ} \mathrm{C}\right)$ than that of PFDDM homopolymer $\left(170^{\circ} \mathrm{C}\right)$, as the content of CTFE in the copolymers is increased, the $T_{g}$ values decreases, as expected.

The average molecular weights of copolymers B1-B4 were calculated by MarkHouwink equation [25] using the intrinsic viscosities of their hexafluorobenzene (HFB) solutions. Although polymers B2-B4 have a great difference in CTFE content, there is no significant difference in average $M W$ (Table 1). However, when the content of CTFE is increased in the copolymers, there is a point where the polymer phase begins to change. Samples B1-B3 are completely amorphous, while sample B4 shows some degree of crystallinity, as evident from its X-ray diffraction peak (Figure 2), indicating a short range of ordered chain structure due to the presence of relatively abundant CTFE units in this polymer. 
Gas permeance is a measure of pressure-normalized flux, an indication of how much gas is actually flowing across the membrane per unit of pressure differential and is expressed in gas permeance units (GPU), with $1 \mathrm{GPU}=10^{-6}$ $\mathrm{cm}^{3}(\mathrm{STP}) /\left(\mathrm{cm}^{2} \cdot \mathrm{s} \cdot \mathrm{cmHg}\right)=7.50 \times 10^{-12} \mathrm{~m}^{3}(\mathrm{STP}) /\left(\mathrm{m}^{2} \cdot \mathrm{s} \cdot \mathrm{Pa}\right) \cdot$ Gas permeation through a dense polymer membrane follows a solution-diffusion mechanism [27]. The pressure and thickness normalized flux or permeability of gas $A\left(P_{A}\right)$ through a polymer is an intrinsic property of that polymer. The permeability is equal to be the product of the solubility of the gas in the polymer $\left(S_{A}\right)$ and the diffusion coefficient for this gas through the polymer $D_{A}\left(P_{A}=D_{A} S_{A}\right)$. Thus the selectivity of gases $A$ and $B$ is expressed as $D_{A} S_{A} / D_{B} S_{B}$.

The results of gas permeance and selectivity tests for the membranes prepared with poly(PFMDD-co-CTFE) copolymers, as well as those for the commercial perfluoropolymers and membranes fabricated from the copolymer poly(PFMDDco-PFMD), are summarized in Table 2. Our previously reported poly(PFMDD-coPFMD) A (57 mol\% PFMDD and 43 mol\% PFMD) shows much better gas selectivity compared to the commercial perfluoropolymers, while still maintaining a comparable gas permeances [3]. For poly(PFMDD-co-CTFE) B1 and B2, there is little apparent difference in gas separation performance, because they are very close in copolymer composition (Table 1); however, when the amount of CTFE increases to $30 \%$ (B3), there is a drastic increase in selectivity reaching 210,480 , and 48 for the gas pairs $\mathrm{H}_{2} / \mathrm{CH}_{4}, \mathrm{He} / \mathrm{CH}_{4}$, and $\mathrm{CO}_{2} / \mathrm{CH}_{4}$, respectively. While the $\mathrm{CO}_{2} / \mathrm{CH}_{4}$ selectivities of poly(PFMDD-co-CTFE) and poly(PFMDD-co-PFMD) are similar (48 vs 47), these is a great improvement of $\mathrm{H}_{2} / \mathrm{CH}_{4}$ and $\mathrm{He} / \mathrm{CH}_{4}$ 
selectivities from poly(PFMDD-co-PFMD) to poly(PFMDD-co-CTFE) (210 vs 130 and 480 vs 260 , for $\mathrm{H}_{2} / \mathrm{CH}_{4}$ and $\mathrm{He} / \mathrm{CH}_{4}$, respectively). These values are far superior relative to those of the commercial fluoropolymers. Typically, the light gas size selectivity of polymeric membranes follows a trade-off relationship [14, 28]: more permeable membranes have lower size selectivity, and vice versa. The results in Table 2 show this trade-off relationship: copolymer B3 has improved $\mathrm{H}_{2} / \mathrm{CH}_{4}$ and $\mathrm{He} / \mathrm{CH}_{4}$ selectivities compared to copolymer A and commercial fluoropolymers but lower $\mathrm{H}_{2}$ and He permeances. However, copolymer A and copolymer B3 have comparable gas permeances while possessing much higher gas selectivities compared to commercial perfluoropolymers, thus they can achieve combinations of permeances and selectivities not attainable with the commercial fluoropolymers.

As reported previously, when the content of monomer PFMD increases in poly(PFMDD-co-PFMD), the selectivity of $\mathrm{N}_{2}, \mathrm{H}_{2}, \mathrm{He}$, and $\mathrm{CO}_{2}$ over $\mathrm{CH}_{4}$ greatly increases [3]. For poly(PFMDD-co-CTFE), from samples B1 to B3, the same trend was observed: when the amount of CTFE in the copolymer is increased, the gas selectivity increases (Table 2 ). This result can be explained by the copolymer structure. From wide angle X-ray (WAXD) measurements, PFMD is able to pack better than the bulky PFMDD [29]. Thus the addition of PFMD produces a more size selective copolymer, presumably by reducing the solubility and diffusion coefficients of $\mathrm{CH}_{4}$ more as compared to other gases such as $\mathrm{N}_{2}$, $\mathrm{H}_{2}, \mathrm{He}$, and $\mathrm{CO}_{2}$. As a result, the selectivities of gas pair of $\mathrm{H}_{2} / \mathrm{CH}_{4}, \mathrm{He} / \mathrm{CH}_{4}$ and $\mathrm{CO}_{2} / \mathrm{CH}_{4}$ are greatly increased as PFMD content increases. CTFE appears to 
behave in a similar way as a selectivity enhancer. For poly(PFMDD-co-CTFE), as the content of CTFE in the copolymer increases, the polymer chains pack more efficiently, and thus the solubility and diffusion of $\mathrm{CH}_{4}$ is greatly reduced compared to $\mathrm{H}_{2}$, $\mathrm{He}$ and $\mathrm{CO}_{2}$. Consequently, the gas selectivities for $\mathrm{H}_{2} / \mathrm{CH}_{4}$ and $\mathrm{He} / \mathrm{CH}_{4}$ are greatly increased, reaching 210 and 480 , respectively, for the copolymer B3 with 30 mol\% of CTFE.

However, further increasing the amount of CTFE in the copolymer appears to have an negative effect on the membrane selectivity. When the content of CTFE in polymer is increased to $52 \mathrm{~mol} \%$, the selectivities of $\mathrm{H}_{2} / \mathrm{CH}_{4}, \mathrm{He} / \mathrm{CH}_{4}$, and $\mathrm{CO}_{2} / \mathrm{CH}_{4}$ are reduced, compared to that of the copolymer with $30 \mathrm{~mol} \%$ CTFE as shown in Table 2. As mentioned previously, when the amount of CTFE in the copolymers reaches about $50 \mathrm{~mol} \%$, there is a significant amount of the crystalline phase, as evident by the X-ray diffractogram shown in Figure 2. This increased crystallinity likely results in defective membranes, leading to reduced gas selectivity. Nevertheless, when the content of CTFE is less than $50 \mathrm{~mol} \%$, the copolymer is amorphous and yields membranes with very attractive separation properties.

These preliminary findings demonstrate the potential of poly(PFMDD-co-CTFE) as an industrially important material for $\mathrm{CO}_{2}$ removal and He recovery from natural gas. We are currently testing mixed gas separation performance under industrially relevant conditions. 


\section{Conclusion}

We have prepared and characterized new fluorinated polymers poly(PFMDD-coCTFE) with different compositions, and investigated their physical and gas separation properties. The new copolymers have improved selectivities compared to the recently studied poly(PFMDD-co-PFMD), and show far superior performance compared to the commercial perfluoropolymers for the separation of gas pairs of $\mathrm{H}_{2} / \mathrm{CH}_{4}, \mathrm{He} / \mathrm{CH}_{4}$, and $\mathrm{CO}_{2} / \mathrm{CH}_{4}$. The gas separation performance of membranes based on the new poly(PFMDD-Co-CTFE) depends strongly on the copolymer composition. Increasing the amount of CTFE up to $30 \mathrm{~mol} \%$ enhances the gas size selectivity. Membranes based on $70 \mathrm{~mol} \%$ PFMDD and $30 \mathrm{~mol} \%$ CTFE show $\mathrm{H}_{2} / \mathrm{CH}_{4}$ and $\mathrm{He} / \mathrm{CH}_{4}$ selectivities of 210 and 480 , respectively, far exceeding the performance of the known perfluoropolymer based membranes. These results demonstrate the potential of the new copolymer poly(PFMDD-coCTFE) as an industrially important material for membrane-based gas separations.

\section{Experimental}

\subsection{Materials}

Hexafluorobenzene (HFB), perfluoro-2-butyltetra hydrofuran Fluorinert® FC-75 (FC-75), chlorotrifluoroethylene (CTFE) were purchased from SynQuest, Inc. PFMDD and perfluorobenzoyl peroxide (PFBP) were synthesized according to methods described in our previous papers [26, 30-32]. All other solvents were purchased from Sigma-Aldrich, Inc. and were used as received. All gases used for gas permeation test were supplied by Praxair (Newark, CA). 


\subsection{Polymerization}

The radical copolymerization of PFMDD and CTFE was carried out in HFB using PFBP as the initiator in a thick glass tube or in an autoclave. In a typical experiment, the CTFE gas was bubbled into HFB at $6-10^{\circ} \mathrm{C}$ and the amount of CTFE dissolved in HFB was determined by weight difference. The perfluoro monomer and initiator dissolved in HFB were then mixed with the CTFE solution in a thick glass tube, which was quickly evacuated and subsequently sealed. Polymerization was carried out at $60^{\circ} \mathrm{C}$ for 24 hours, and then it was heated further at $80^{\circ} \mathrm{C}$ for 2 hours. The resulting solution was concentrated and then added to an excess amount of dichloromethane. The precipitated polymer was then filtered, washed with tetrahydrofuran, and dried under vacuum overnight.

\subsection{Characterization}

${ }^{19} \mathrm{~F}$ NMR spectra were recorded using a Bruker $400 \mathrm{MHz}$ Spectrometer at $20^{\circ} \mathrm{C}$. Perfluoro polymer samples were dissolved in HFB in NMR tubes and an insert filled with $\mathrm{CDCl}_{3}$ was used for the filed lock. The percentage of CTFE monomer in copolymers was estimated by using the NMR integration data of poly(PFMDDco-CTFE) copolymers and that of the PFMDD homopolymers. The copolymer composition was also calculated by elemental analysis using the $\mathrm{Cl}$ content determined by Atlantic Microlab, Inc, with $a \pm 0.3 \%$ accuracy and precision. 
The average molecular weight of the copolymer was estimated by measuring the viscosity of the polymer dissolved in HFB and using the viscosity data of perfluoro polymers of known molecular weight. The viscosity of polymer solution was measured in a Ubbelohde viscometer and the intrinsic viscosity was derived from Huggins Equation [33]. The average molecular weight was calculated based on Mark-Houwink equation [25]. Each measurement was repeated and the average value was reported.

Differential scanning calorimetry (DSC) measurements were performed using a DSC 2920 module with TA Instrument 5100 system. Samples weighing 7-15 mg were placed in the pan of the DSC. The glass transition temperature $\left(T_{g}\right)$ was determined as the inflection point in the endothermic jump in the second heating scan. The reported $\mathrm{Tg}$ value is the average of that from two measurements.

The powder X-ray diffraction data were collected on a Bruker D8 DISCOVER GADDS microdiffractometer equipped with a VANTEC-2000 area detector in a $\varphi$ rotation method. The X-ray generated from a sealed $\mathrm{Cu}$ tube is monochromated by a graphite crystal and collimated by a $0.5 \mathrm{~mm}$ MONOCAP ( $\lambda$ Cu-Ka $=1.54178$ A). Polymer powder was ground and sandwiched between two thin plastic films, and then loaded on a loop holder and mounted on a magnetic base. The sampledetector distance is $150 \mathrm{~mm}$, and the exposure time is 600 seconds per run. Data were integrated by the XRD2EVAL program in the Bruker PILOT software.

\subsection{Membrane preparation and gas permeation test}


Composite membranes were prepared by dissolving the copolymer in HFB or Fluorinert $\AA^{\circledR}$ FC-75 and coating the resulting solution on a microporous poly(acrylonitrile) ultrafiltration substrate by a laboratory-scale dip coating machine. The thickness of the membrane is estimated to be $0.2-1$ micron. After the coating and drying, the film was heated to near the $T_{g}$ of the copolymer for several hours to remove any residual solvent [3].

For comparison with the poly(PFMDD-co-CTFE) membrane, composite membranes with other perfluoro selective layers (perfluoro dioxolane copolymers, Teflon® AF 2400, Hyflon® AD 60, and Cytop ${ }^{\mathrm{TM}}$ ) were also prepared with the same configuration.

The gas permeation properties of the perfluoro polymer composite membranes were determined at $22{ }^{\circ} \mathrm{C}$ using a variable volume test apparatus with a feed pressure of $50 \mathrm{psig}$ and a permeate pressure of 0 psig. The membrane samples were housed in a Millipore $47 \mathrm{~mm}$ diameter test cell $\left(13.8 \mathrm{~cm}^{2}\right.$ of membrane area) and permeate gas flow rates were measured with a soap film bubble flow meter. The compositions of feed, residue, and permeate gas streams were analyzed by gas chromatography (GC), as shown in Figure 3.

\section{Acknowledgement}

This research was supported partially by NSF through the Grant No. 11P1149053. We thank Dr. Chunhua Hu at the NYU Department of Chemistry X-ray Diffraction Facility for his assistance with X-ray diffraction measurements. 


\section{References}

[1] D.E. Sanders, Z.P. Smith, R. Guo, L.M. Robeson, J.E. McGrath, D.R. Paul, B.D. Freeman, Polymer, 54 (2013) 4729-4761.

[2] J.G. Drobny, Technology of fluoropolymers, 2nd ed., CRC Press, Boca Raton, FL, 2009.

[3] Y. Okamoto, H. Zhang, F. Mikes, Y. Koike, Z.J. He, T.C. Merkel, J. Membr. Sci., 471 (2014) 412-419.

[4] I. Pinnau, L.G. Toy, J. Membr. Sci., 109 (1996) 125-133.

[5] A.Y. Alentiev, Y.P. Yampolskii, V.P. Shantarovich, S.M. Nemser, N.A. Plate, J. Membr. Sci., 126 (1997) 123-132.

[6] V. Arcella, P. Colaianna, P. Maccone, A. Sanguineti, A. Gordano, G. Clarizia, E. Drioli, J. Membr. Sci., 163 (1999) 203-209.

[7] V.I. Bondar, B.D. Freeman, Y.P. Yampolskii, Macromolecules, 32 (1999) 6163-6171.

[8] T.C. Merkel, V. Bondar, K. Nagai, B.D. Freeman, Macromolecules, 32 (1999) 370-374.

[9] T.C. Merkel, V. Bondar, K. Nagai, B.D. Freeman, Y.P. Yampolskii, Macromolecules, 32 (1999) 8427-8440.

[10] A.Y. Alentiev, V.P. Shantarovich, T.C. Merkel, V.I. Bondar, B.D. Freeman, Y.P. Yampolskii, Macromolecules, 35 (2002) 9513-9522.

[11] V. Arcella, A. Ghielmi, G. Tommasi, High performance perfluoropolymer films and membranes, in: N.N. Li, E. Drioli, W.S.W. Ho, G.G. Lipscomb (Eds.) Advanced Membrane Technology, New York Academy of Sciences, New York, 2003, pp. 226-244.

[12] R.S. Prabhakar, B.D. Freeman, I. Roman, Macromolecules, 37 (2004) 76887697.

[13] Z. Cui, E. Drioli, Y.M. Lee, Prog. Polym. Sci., 39 (2014) 164-198.

[14] L.M. Robeson, J. Membr. Sci., 62 (1991) 165-185.

[15] J. Scheirs, Modern fluoropolymers: high performance polymers for diverse applications, Wiley, Sussex, UK, 1997.

[16] G. Hougham, P. Cassidy, K. Johns, J. Davidson, Fluoropolymers: synthesis and applications, Plenum Press, New York, 1999.

[17] S. Ebnesajjad, Fluoroplastics, Volume 1: Non-Melt Processible

Fluoropolymers-The Definitive User's Guide and Data Book, 2nd ed., Elsevier, Oxford, UK, 2015.

[18] G.J. Samuels, G.J. Shafer, T. Li, C.A. Threlfall, N. Iwamoto, E.J. Rainal, Copolymers for barriers, U.S. Patent 8,163,858, 2012.

[19] F. Boschet, B. Ameduri, Chem. Rev., 114 (2014) 927-980.

[20] B. Ameduri, B. Boutevin, Well-Architectured Fluoropolymers: Synthesis, Properties and Applications, Elsevier, Oxford, UK, 2004.

[21] F. Mikes, H.X. Teng, G. Kostov, B. Ameduri, Y. Koike, Y. Okamoto, J. Polym. Sci., Part A: Polym. Chem., 47 (2009) 6571-6578.

[22] A. Alaaeddine, F. Boschet, B. Ameduri, J. Polym. Sci., Part A: Polym. Chem., 52 (2014) 1721-1729.

[23] G. Couture, V. Ladmiral, B. Ameduri, J. Fluorine Chem., 171 (2015) 124-132. 
[24] G. Lopez, A. Thenappan, B. Ameduri, Acs Macro Letters, 4 (2015) 16-20.

[25] P.C. Hiemenz, T.P. Lodge, Polymer chemistry, CRC press, Boca Raton, FL, 2007.

[26] F. Mikes, Y. Yang, I. Teraoka, T. Ishigure, Y. Koike, Y. Okamoto, Macromolecules, 38 (2005) 4237-4245.

[27] W.B. Richard, Membrane technology and applications, 3rd ed., John Wiley \& Sons Ltd, West Sussex, UK, 2012.

[28] B.D. Freeman, Macromolecules, 32 (1999) 375-380.

[29] K. Koike, F. Mikes, H. Zhang, Y. Koike, Y. Okamoto, J. Fluorine Chem., 156 (2013) 198-202.

[30] W.H. Liu, F. Mikes, Y.Z. Guo, Y. Koike, Y. Okamoto, J. Polym. Sci., Part A:

Polym. Chem., 42 (2004) 5180-5188.

[31] W.H. Liu, Y. Koike, Y. Okamoto, Macromolecules, 38 (2005) 9466-9473.

[32] Y. Yang, F. Mikes, L. Yang, W.H. Liu, Y. Koike, Y. Okamoto, J. Fluorine

Chem., 127 (2006) 277-281.

[33] M.L. Huggins, J. Am. Chem. Soc., 64 (1942) 2716-2718. 


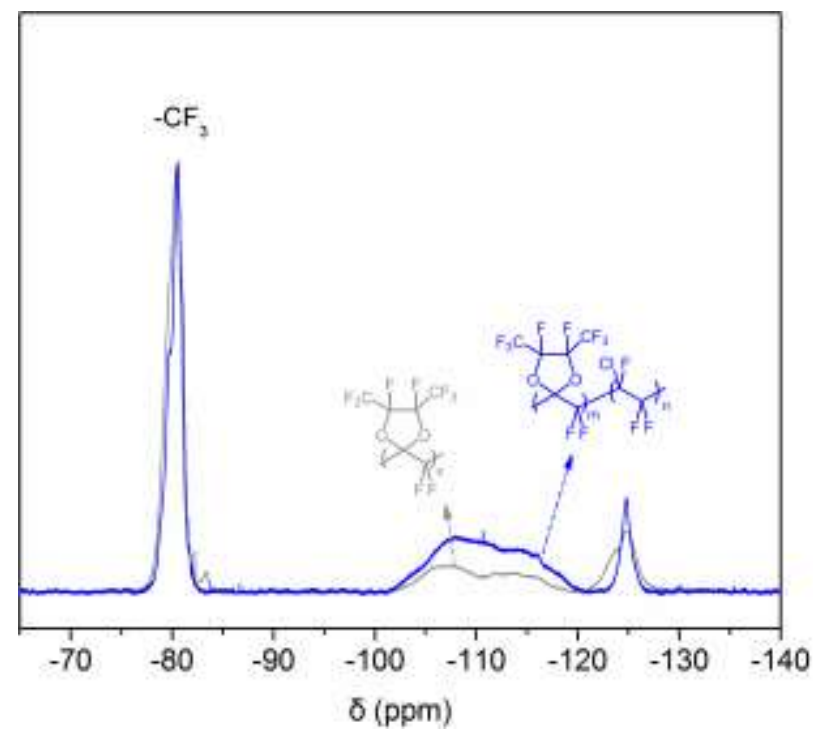

Figure 1. The ${ }^{19} \mathrm{~F}$ NMR (400 MHz) spectrum of poly(PFMDD-co-CTFE) $(70 \mathrm{~mol} \%$ PFMDD and 30 mol\% CTFE) superimposed on that of the PFMDD homopolymer. 


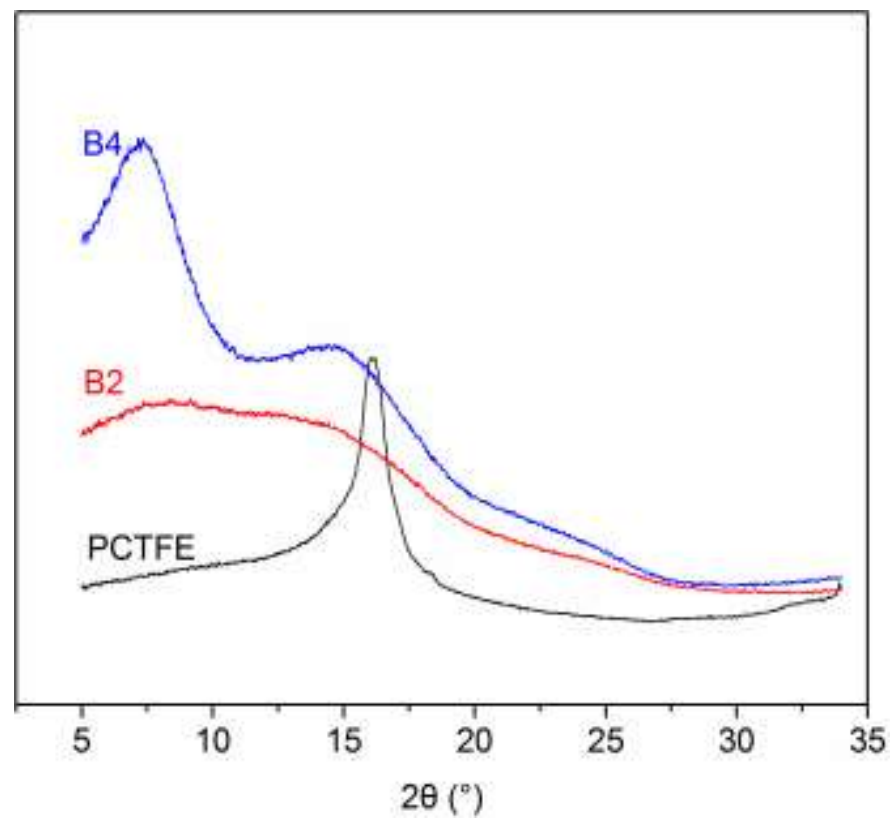

Figure 2. Powder X-ray diffractgrams of PCTFE, 83 mol\% PFMDD-17 mol\% CTFE poly(PFMDD-co-CTFE) (B2) and 48 mol\% PFMDD-52 mol\% CTFE poly(PFMDD-co-CTFE) (B4) samples. 


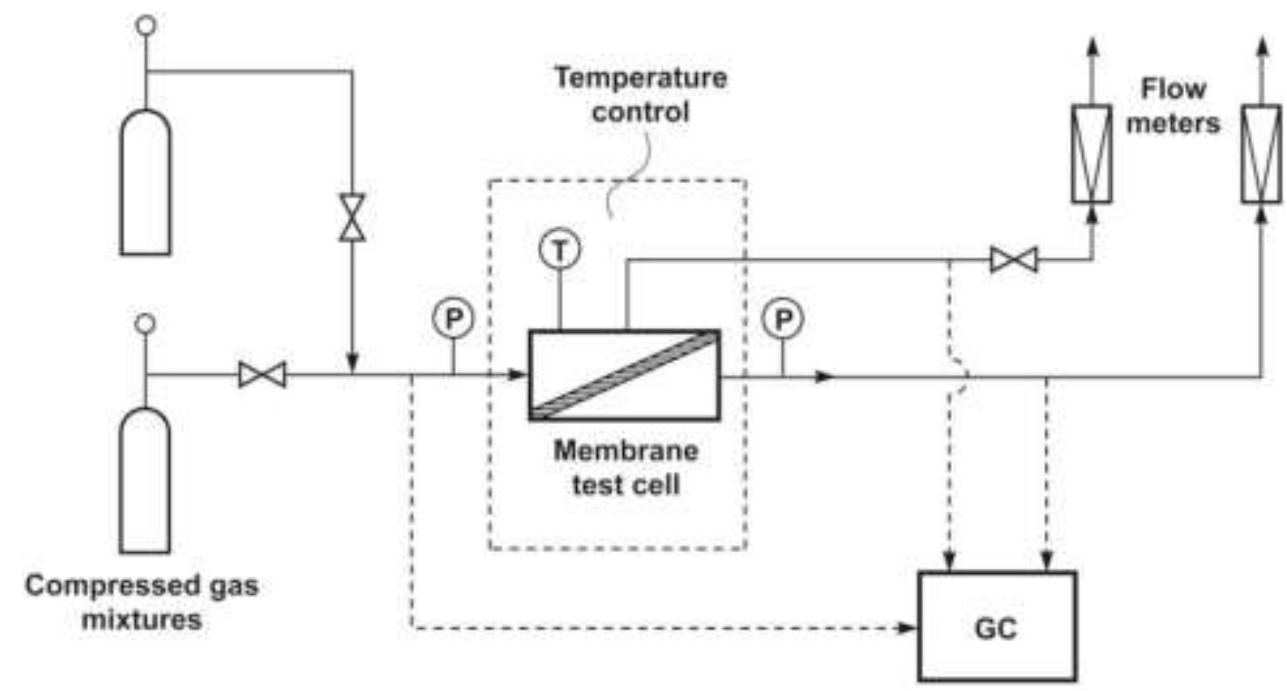

Figure 3. Schematic of the gas permeation test system for membrane samples. 


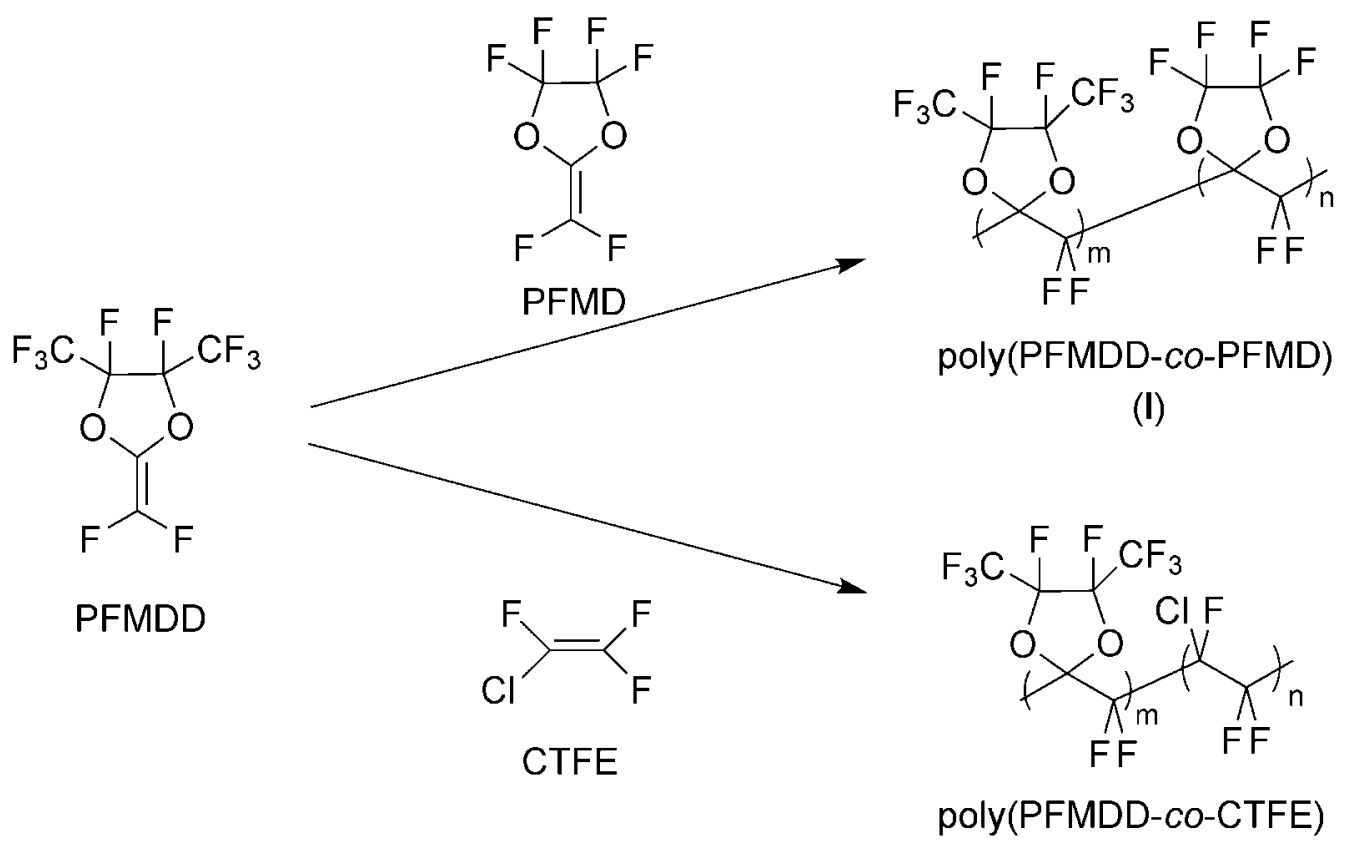

(II)

Scheme 1. The chemical structures of monomers PFMDD, PFMD, CTFE and copolymers poly(PFMDD-co-PFMD) and poly(PFMDD-co-CTFE). 
Table 1

The physical properties of poly(PFMDD-co-CTFE) copolymers

\begin{tabular}{|c|c|c|c|c|c|c|c|}
\hline \multirow[t]{2}{*}{ Sample } & \multirow[t]{2}{*}{$\begin{array}{l}\text { CTFE in feed } \\
(\text { mol\%) }\end{array}$} & \multicolumn{2}{|c|}{$\begin{array}{c}\text { CTFE in } \\
\text { copolymer (mol\%) }\end{array}$} & \multirow[t]{2}{*}{$\begin{array}{c}T_{g} \\
\left({ }^{\circ} \mathrm{C}\right)\end{array}$} & \multirow{2}{*}{$\begin{array}{l}\text { Intrinsic } \\
\text { Viscosity } \\
(\mathrm{dL} / \mathrm{g})^{\mathrm{c}}\end{array}$} & \multirow[t]{2}{*}{$\begin{array}{l}\text { Average } \\
M W^{\mathrm{d}}\end{array}$} & \multirow[t]{2}{*}{ phase } \\
\hline & & $\mathrm{NMR}^{\mathrm{a}}$ & $E A^{b}$ & & & & \\
\hline B1 & 20 & 12 & 10 & 152 & 0.0175 & 300,000 & amorphous \\
\hline B2 & 20 & 17 & 11 & 152 & 0.0315 & 360,000 & amorphous \\
\hline B3 & 35 & 30 & 28 & 132 & 0.0375 & 387,000 & amorphous \\
\hline B4 & 60 & 52 & 50 & 120 & 0.0350 & 380,000 & $\begin{array}{l}\text { partially } \\
\text { crystalline }\end{array}$ \\
\hline
\end{tabular}

a Estimated from NMR integrals, $10 \%$ error.

${ }^{b}$ Based on $\mathrm{Cl}$ data; $\pm 0.3 \%$ accuracy and precision.

${ }^{c}$ Average value from repeated measurements, in HFB at $25^{\circ} \mathrm{C}$.

${ }^{\mathrm{d}}$ Estimated $M W$ from the viscosity measurement [26]. 
Table 2

Pure-gas permeances and selectivities for various fluoropolymer-based membranes $^{a}$

\begin{tabular}{|c|c|c|c|c|c|c|c|c|}
\hline \multirow{2}{*}{$\begin{array}{c}\text { Membrane } \\
\text { selective layer } \\
\text { polymer }\end{array}$} & \multicolumn{4}{|c|}{ Permeance (GPU) } & \multicolumn{4}{|c|}{ Selectivity } \\
\hline & $\mathrm{N}_{2}$ & $\mathrm{H}_{2}$ & $\mathrm{He}$ & $\mathrm{CO}_{2}$ & $\mathrm{~N}_{2} / \mathrm{CH}_{4}$ & $\mathrm{H}_{2} / \mathrm{CH}_{4}$ & $\mathrm{He} / \mathrm{CH}_{4}$ & $\mathrm{CO}_{2} / \mathrm{CH}_{4}$ \\
\hline Teflonß AF 2700 & 2,700 & 10,500 & 10,500 & 13,000 & 1.2 & 4.6 & 4.6 & 5.7 \\
\hline Hyflon® AD60 & 180 & 1,700 & 2,600 & 1,330 & 2.4 & 23 & 35 & 18 \\
\hline Cytop ${ }^{\mathrm{TM}}$ & 18 & 290 & 790 & 150 & 3.0 & 48 & 130 & 25 \\
\hline Copolymer $A^{b}$ & 29 & 700 & 1,400 & 260 & 5.3 & 130 & 260 & 47 \\
\hline Copolymer B1c & 42 & 580 & 1,010 & 320 & 2.5 & 34 & 60 & 19 \\
\hline Copolymer B2c & 33 & 450 & 610 & 245 & 2.2 & 30 & 54 & 16 \\
\hline Copolymer B3c & 9.8 & 340 & 770 & 78 & 6.1 & 210 & 480 & 48 \\
\hline Copolymer B4c & 8.1 & 210 & 520 & 72 & 3.1 & 82 & 201 & 28 \\
\hline
\end{tabular}

a Each measurement was repeated and the average value was reported.

b Copolymer A: copolymer of PFMDD (57 mol\%) and PFMD (43 mol\%) [3].

c Copolymer B: poly(PFMDD-co-PFMD) with various CTFE content (Table 1). 